\title{
Management of a Parturient with Preeclampsia and HELLP Syndrome Complicated by Gestational Diabetes Insipidus
}

\author{
Kalpana Tyagaraj ${ }^{1}$, Alexandra Mazur ${ }^{2}$, Agnes Miller ${ }^{1}$, Dennis Feierman' ${ }^{1}$ \\ ${ }^{1}$ Department of Anesthesiology, Maimonides Medical Center, Brooklyn, NY, USA \\ ${ }^{2}$ Formerly Affiliated Department of Anesthesiology, Cedars Sinai Medical Center, Los Angeles, CA, USA \\ Email: kalpana_tyagaraj@msn.com
}

How to cite this paper: Tyagaraj, K., Mazur, A., Miller, A. and Feierman, D. (2016) Management of a Parturient with Preeclampsia and HELLP Syndrome Complicated by Gestational Diabetes Insipidus. Open Journal of Anesthesiology, 6, 175-180.

http://dx.doi.org/10.4236/ojanes.2016.610026

Received: September 5, 2016

Accepted: September 27, 2016

Published: September 30, 2016

Copyright $\odot 2016$ by authors and Scientific Research Publishing Inc. This work is licensed under the Creative Commons Attribution International License (CC BY 4.0).

http://creativecommons.org/licenses/by/4.0/

\begin{abstract}
HELLP syndrome (Hemolysis, Elevated Liver enzymes, Low Platelets) is considered to be a variant or severe form of pre-eclampsia, a life threatening complication of pregnancy. Gestational Diabetes Insipidus (GDI) can coexist with severe preeclampsia and HELLP syndrome. The combination of these two conditions presents a unique challenge to the anesthesiologist and the obstetric team, caring for this parturient. We present the case of a parturient with an unusual presentation of GDI, coexisting with severe preeclampsia and HELLP syndrome. She had two days history of polyuria and polydipsia as well as lethargy and rapidly rising serum sodium in addition to acute renal failure without any neurologic symptoms. Expeditious delivery of the baby and supportive management is essential for optimal outcomes. She underwent a repeat Cesarean section under combined spinal epidural (CSE) anesthesia. This patient was discharged on postoperative day five after clinical resolution of her signs and symptoms.
\end{abstract}

\section{Keywords}

Gestational Diabetes Insipidus, Severe Preeclampsia, HELLP Syndrome

\section{Introduction}

Preeclampsia is a multisystem, progressive, highly variable disorder unique to pregnancy and a leading cause of maternal and fetal/neonatal morbidity and mortality. Preeclampsia, defined as systolic blood pressure greater than 140 and diastolic blood pressure greater than 90 after twenty weeks of gestation accompanied by proteinuria ( $>300 \mathrm{mg} / \mathrm{d}$ ), complicates about $10 \%$ of pregnancies. In the United States, preeclampsia 
complicates $6 \%-10 \%$ of all pregnancies; the incidence is believed to be even higher in underdeveloped countries. Hypertension is the most common medical disorder of pregnancy and is a leading cause of maternal and fetal morbidity and mortality. Severe preeclampsia can be associated with blood pressures greater than $160 / 110 \mathrm{~mm}$ of $\mathrm{Hg}$, proteinuria greater than 5 grams/day, oliguria $(<500 \mathrm{~mL} /$ day $)$, elevated serum creatinine, intrauterine growth restriction, pulmonary edema, neurologic manifestations of headache, visual disturbances, seizures, or stroke as well as hepatic tenderness or HELLP syndrome. Recent evidence suggests that preeclampsia accounts for approximately $15.9 \%$ of all maternal deaths in the United States and is a major cause of perinatal morbidity and death. GDI is known to be associated with HELLP and HELLP is known to be associated with GDI; the combination is rare and complicates the management.

In pregnant women, GDI has been described as a rare complication of pregnancy that occurs in about 4 out of 100,000 pregnancies [1]. The mechanism of GDI is that maternal antidiuretic hormone is degraded by the vasopressinase enzyme secreted by placental trophoblasts and it can manifest as early as the seventh week of gestation [2].

The definitive therapy to prevent further progression of the severe preeclampsia and GDI is delivery of the fetus and the placenta. The anesthetic goals of management are geared towards treatment to minimize vasospasm, achieve blood pressure control, improve circulation, optimize intravascular volume and correct electrolyte and acid base disturbances without over correcting the hypernatremia.

\section{Case Report}

The patient has given consent to publish this case report. A 41-year-old African American female, G3P3, with no significant past medical problems and history of two previous Cesarean sections, presented at 38 weeks of gestational age to the patient presented to obstetrical clinic. Her presenting com-plaints were polyuria, polydipsia, weakness, and headache of two days duration. On examination, she was found to have elevated blood pressures, systolic blood pressure ranging from $160-170 \mathrm{~mm}$ of $\mathrm{Hg}$, diastolic blood pressures $90-100 \mathrm{~mm}$ of $\mathrm{Hg}$ and heart rate in the range of $100-120$ beats per minute. She denied any blurring of vision, epigastric pain, neurological abnormalities or breathing difficulties. Examination of the systems did not reveal any significant findings.

On admission, her hematocrit was 42 and platelets were 235,000. Her Liver function tests were abnormal and revealed Serum AST(aspartate aminotransferase) of $270 \mathrm{IU} / \mathrm{L}$, ALT (alanine aminotransferase) of $271 \mathrm{IU} / \mathrm{L}, \mathrm{LDH}$ (lactate dehydrogenase) of $379 \mathrm{IU} / \mathrm{L}$, Alkaline phosphatase $207 \mathrm{IU} / \mathrm{L}$, Albumin $2.9 \mathrm{IU} / \mathrm{L}$ and total bilirubin $0.7 \mathrm{mg} / \mathrm{dl}$. Renal function tests revealed elevated uric acid of $8.9 \mathrm{mg} / \mathrm{dl}$, BUN (blood urea nitrogen) of 15 $\mathrm{mg} / \mathrm{dl}$ and elevated creatinine of $1.2 \mathrm{mg} / \mathrm{dl}$. Serum electrolytes showed elevated sodium of $148 \mathrm{mmols} / \mathrm{L}$ and chloride $121 \mathrm{mmols} / \mathrm{L}$, and potassium $4.6 \mathrm{mmols} / \mathrm{L}$. Her PT and PTT were within normal limits (10.7 and 26.4 seconds). Pelvic examination revealed cephalic fetal presentation, cervical dilatation of $0 \mathrm{cms}$ and intact membranes. Bedside Ultrasound examination showed vertex presentation, anterior placenta, BPP 6/8 and 
AFI $2.7 \mathrm{cms}$.

A diagnosis of HELLP syndrome with severe oligohydramnios was made. In the presence of HELLP syndrome, severe oligohydramnios and elevated sodium and chloride in the setting of polyuria and polydipsia, the decision was to proceed with repeat C-Section for expeditious delivery of the fetus and the placenta. Patient received a bolus of 4 grams of magnesium sulfate for eclampsia prophylaxis. Two units of PRBCs were typed and cross-matched.

Patient was placed on standard ASA monitors in the operating room. Additionally, a 20 gauge arterial line was inserted for continuous blood pressure monitoring and repetitive blood sampling for electrolytes. Combined Spinal Epidural(CSE) was per-formed at 3 - 4 lumbar interspace with preservative free morphine $0.3 \mathrm{mg}$, fentanyl $15 \mathrm{ug}$, and $1.5 \mathrm{ml}$ of hyperbaric bupivacaine $0.75 \%$ with dextrose $8.5 \mathrm{mg} / \mathrm{ml}$. Left uterine displacement was done. Cesarean section course was uncomplicated. A healthy baby boy with APGAR scores of 7 and 9 was delivered. Intraoperative fluid management consisted of the administration of $2200 \mathrm{ml}$ of lactated Ringers over a period of 100 minutes.

Immediate postoperative course was complicated by the rapidly rising serum sodium with high calculated Serum Osmolality of 331 in the context of renal failure and urine output $>2000 \mathrm{ml}$ over a period of 5 hours. She was transferred to the medical intensive care unit for hydration, blood pressure monitoring and correction of hypernatremia. $0.9 \%$ normal saline infusion at $300 \mathrm{ml} / \mathrm{hr}$ was initiated, which was titrated to achieve a goal of sodium correction rate of less than $10 \mathrm{mEq}$ in twenty four hours or $0.5 \mathrm{mEq} / \mathrm{hr}$. Serum sodium levels were checked every two hours. On postoperative day one, the hypernatremia peaked at 163 meqs and decreased with hydration to 153 meqs. The hepatic enzyme levels peaked at aspartate transaminase and alanine transaminase levels of 1359 and 848 and had decreased significantly by day 3 . Her serum creatinine peaked at 1.8 and gradually decreased (Table 1 ). Her pan cultures were negative.

Both Endocrinology and Neurology consults were obtained. The antidiuretic hormone, follicle stimulating hormone, luteinizing hormone, and adrenocorticotropic hormone levels were assayed. Serum ADH level was $<1.0$ pg/ml (normal range 1 - 13.3 $\mathrm{pg} / \mathrm{ml}$ ). Magnetic resonance imaging/magnetic resonance angiogram of the brain was

Table 1. Patients daily laboratory results.

\begin{tabular}{ccccccc}
\hline \multirow{2}{*}{ Peak Serum levels } & \multicolumn{7}{c}{ Postoperative Day (POD) $^{\mathrm{a}}$} \\
\cline { 2 - 7 } & POD 0 & POD 1 & POD 2 & POD 3 & POD4 & POD 5 \\
\hline Sodium (mmols/L) & 147 & 163 & 152 & 143 & 142 & 141 \\
Creatinine (mg/dl) & 1.2 & 1.8 & 1.6 & 1.3 & 0.9 & 1.0 \\
ALT (IU/L) & 271 & 848 & 473 & 249 & - & 105 \\
AST (IU/L) & 270 & 1359 & 449 & 141 & - & 38 \\
LDH (IU/L) & 379 & 1480 & - & - & - & 142 \\
Uric acid (mg/dl) & 8.9 & 11.5 & - & - & - & 6.8 \\
\hline
\end{tabular}

a. Patients daily laboratory results. ALT: alanine aminotransferase; AST: aspartate aminotransferase; LDH: lactate dehydrogenase; IU: international Units. 
negative for pituitary pathology and there was no evidence for posterior reversible encephalopathy syndrome. She was diagnosed, by exclusion, with gestational diabetes insipidus (GDI). Desmopressin was not administered due to rapid, clinical improvement, decreasing serum sodium levels, decreasing urine output and no neurologic deficits. Optimization of blood pressure with labetalol was continued, and she was maintained on magnesium sulfate infusion for seizure prophylaxis.

On postoperative day two, the sodium and creatinine normalized, her urine output decreased, and the Foley catheter was removed. On postoperative day three, the patient's liver function tests profile normalized. On postoperative day four, she was transferred to the regular maternity floor. On postoperative day five (POD), the patient was discharged with normal labs on labetalol $100 \mathrm{mg}$ PO every 12 hours with an electronic blood pressure monitoring device. Patient was discharge home POD 6, and post-partum follow after 2 weeks was uneventful.

\section{Discussion}

Diabetes insipidus during pregnancy is a rare phenomenon and its incidence varies from two to six cases per 100,000 pregnancies. It can occur at any stage of the gestation, but commonly presents at the end of the second or during the third trimester of a first pregnancy. Occasionally, it can manifest in the postpartum period.

DI can be the manifestation of several factors, the most frequent being a deficit in the secretion of $\mathrm{ADH}$ (Antidiuretic Hormone) from the hypothalamus, which results in neurogenic or central diabetes insipidus (DI). The second cause is renal tubular insensitivity to ADH (antidiuretic hormone), nephrogenic or peripheral DI. The third variety is the result of a deficit in $\mathrm{ADH}$ production, secondary to excessive fluid intake because of psychogenic polydipsia. During pregnancy, an abnormal clearance of the hormone can cause $\mathrm{ADH}$ deficiency and result in gestational DI.

Symptoms of DI usually develop over a few days and include polyuria, polydipsia, fatigue, nausea, weight loss, and decreased skin turgor. The symptoms of polyuria and polydipsia may be difficult to distinguish from normal pregnancy as the normal thirst threshold in pregnancy is reduced. In fact, the clinical examination is often normal in patrturients who are drinking fluids without any restriction. Disturbances in hydration become evident in obtunded or comatose patients because of their inability to compensate for increased urinary losses. To differentiate between the various causes of GDI, history of neurosurgical interventions for pituitary tumors and psychological disturbances should be sought.

In a normal pregnant patient, plasma osmolality decreases by almost $10 \mathrm{mmols} / \mathrm{L}$ and sodium concentration by almost $5 \mathrm{meq} / \mathrm{L}$. Urinary osmolality is also decreased. GDI can be suspected when serum osmolality is equivalent to that of a non-pregnant woman $(285 \mathrm{mosmol} / \mathrm{L})$ with urinary osmolality under 300 mosmols/L. Measurement of the vasopressinase serum concentrations is not available commercially, and the diagnosis is usually established based on the clinical presentation and the appropriate laboratory studies. Blood glucose levels are usually normal in GDI. Serum glucose, sodium, $\mathrm{ADH}$ concentration, hepatic transaminases, creatinine and uric acid, all need to 
be measured. Plasma levels of ADH should be assayed in the presence of a vasopressinase inhibitor since parturients have high concentrations of cysteine aminopeptidase which degrades vasopressin in vitro. Urine volume, urinary electrolytes including sodium and glucose and osmolality need to be measured.

Goals of Anesthetic management in a parturient with HELLP syndrome and GDI (both have similar perioperative management goals, each has its own particular management that does not interfere with the management of the other condition):

The focus of perioperative management is on:

- Blood pressure control with appropriate antihypertensive medications;

- Seizure prophylaxis with Magnesium therapy;

- Strict intake-output monitoring;

- Cautious administration of fluids, avoiding a rapid fall in serum sodium concentration of no more than $0.5 \mathrm{meq} /$ hour to prevent cerebral edema (In HELLP syndrome, over hydration can lead to pulmonary edema, whereas, in DI it can lead to a rapid fall in sodium concentration);

- Treatment with desmopressin;

- Frequent monitoring of serum electrolytes;

- Expeditious delivery of the fetus and placenta (delivery of the placenta alleviates the GDIas well as the HELLP syndrome and preecamplcia.);

- Utilizing spinal/epidural blocks- preferable since monitoring of the mental status and avoidance of the airway is facilitated;

- Invasive hemodynamic monitoring- An arterial line insertion is highly desirable, as it allows for close monitoring of the blood pressure in a severe preeclamptic parturient, but also allows serial estimation of electrolytes. CVP monitoring, though not routinely necessary, will aid in volume resuscitation as needed;

- Continued postoperative care in a monitored setting is highly desirable.

Initially, our parturient was treated with repeated doses of labetalol for blood pressure control and magnesium sulfate for eclampsia prophylaxis, but the definitive treatment for her preeclampsia, HELLP syndrome, and gestational diabetes insipidus was the delivery of fetus and placenta [3]. Treatment with desmopressin was not initiated in this patient due to her rapid improvement. The use of an arterial line not only allows for expeditious monitoring and treatment of elevated blood pressures but also allows for close monitoring of electrolytes and creatinine postoperatively. While not routinely necessary, central venous pressure monitoring in addition to arterial line monitoring has been described in GDI to assist with careful volume resuscitation in the setting of suspected dehydration in a parturient with extreme thirst and severe preeclampsia [4]. It is postulated that hypernatremia leads to increased local anesthetic potency due to the increased intra-extra neural sodium gradient and careful titration and administration of the local anesthetics is essential. If time permitted, fluid resuscitation with an arterial line and central venous pressure monitoring based on her calculated water deficit as well as desmopressin supplementation would have been desirable to at least partially correct the patient's fluid deficit and serum sodium, allowing careful titration of 
epidural anesthesia for Cesarean section [5].

Administration of intranasal desmopressin is the treatment of choice in GDI [6]. Caution should be exercised to avoid desmopressin overdose which can lead to hyponatremia. Patients with gestational diabetes insipidus may require intranasal desmopressin spray $5 \mathrm{mcg}$ twice a day after an initial dose of $10 \mathrm{mcg}$. Breastfeeding can stimulate secretion of ADH and the dose of desmopressin can be decreased. Desmopressin is secreted in the mother's milk in very small quantities and minimally absorbed by the GI tract; hence, poses little risk for fluid and electrolyte disorders in the neonate.

Alternative treatment is hydrochlorothiazide. Potential complications include fetal hypoglycemia and neonatal DI. Remission of DI occurs two to three weeks after delivery and hydrochlorothiazide must be discontinued.

\section{Conclusion}

During pregnancy, the diagnosis of DI is not easy to consider since polyuria in pregnancy is generally considered normal. In general, GDI per se does not seem to result in serious complications. However, certain varieties, especially in association with HELLP syndrome, can have serious consequences and need to be kept in mind. A multidisciplinary, collaborative approach between obstetric anesthesiologists, maternal-fetal medicine specialists, intensivists and neonatologists is essential to weigh the maternal and fetal risks of prolonging the pregnancy versus the potential benefits of expectant management to further fetal maturation.

\section{References}

[1] Davidson, A.J., Morton, N.S., Arnup, S.J., de Graaff, J.C., Disma, N., Withington, D.E., Frawley, G., Hunt, R.W., Hardy, P., Khotcholava, M., von Ungern Sternberg, B.S., Wilton, N., Tuo, P., Salvo, I., Ormond, G., Stargatt, R., Locatelli, B.G. and McCann, M.E. (2015) General Anesthesia Compared to Spinal Anesthesia C: Apnea after Awake Regional and General Anesthesia in Infants: The General Anesthesia Compared to Spinal Anesthesia Study-Comparing Apnea and Neurodevelopmental Outcomes, a Randomized Controlled Trial. Anesthesiology, 123, 38-54.

[2] Barbey, F., Bonny, O., Rothuizen, L., Gomez, F. and Burnier, M. (2003) A Pregnant Woman with de Novo Polyuria-Polydipsia and Elevated Liver Enzymes. Nephrology, Dialysis, Transplantation, 18, 2193-2196. http://dx.doi.org/10.1093/ndt/gfg152

[3] Gambito, R., Chan, M., Sheta, M., Ramirez-Arao, P., Gurm, H., Tunkel, A. and Nivera, N. (2012) Gestational Diabetes Insipidus Associated with HELLP Syndrome: A Case Report. Case Reports in Nephrology, 2012, Article ID: 640365.

[4] Passannante, A.N., Kopp, V.J. and Mayer, D.C. (1995) Diabetes Insipidus and Epidural Analgesia for Labor. Anesthesia and Analgesia, 80, 837-838.

[5] Lacassie, H.J., Muir, H.A., Millar, S. and Habib, A.S. (2005) Perioperative Anesthetic Management for Cesarean Section of a Parturient with Gestational Diabetes Insipidus. Canadian Journal of Anaesthesia, 52, 733-736. http://dx.doi.org/10.1007/BF03016563

[6] Aleksandrov, N., Audibert, F., Bedard, M.J., Mahone, M., Goffinet, F. and Kadoch, I.J. (2010) Gestational Diabetes Insipidus: A Review of an Underdiagnosed Condition. Journal of Obstetrics and Gynaecology Canada, 32, 225-231. http://dx.doi.org/10.1016/S1701-2163(16)34448-6 
Submit or recommend next manuscript to SCIRP and we will provide best service for you:

Accepting pre-submission inquiries through Email, Facebook, LinkedIn, Twitter, etc. A wide selection of journals (inclusive of 9 subjects, more than 200 journals)

Providing 24-hour high-quality service

User-friendly online submission system

Fair and swift peer-review system

Efficient typesetting and proofreading procedure

Display of the result of downloads and visits, as well as the number of cited articles

Maximum dissemination of your research work

Submit your manuscript at: http://papersubmission.scirp.org/

Or contact ojanes@scirp.org 